\title{
A Hypothetical Model to Predict \\ Nursing Students' Perceptions of the Usefulness of Pre-Service Integrated Management of Childhood Illness Training
}

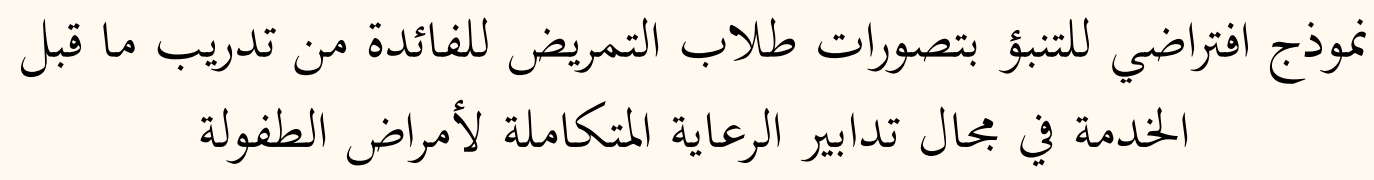

فنة العريمية و ستوات عثمان لنجريال

ABSTRAC T: Objectives: This study aimed to test a hypothetical model to predict nursing students' perceptions of the usefulness of pre-service Integrated Management of Childhood Illness (IMCI) training and their intention to apply this training in clinical practice. Methods: This study was carried out at the Sur Nursing Institute, Sur, Oman, in May 2015. Using six predefined constructs, a hypothetical structural model was created. The constructs were used as latent variables to highlight their probable impact on intention to apply IMCI-related knowledge and skills in practice. A structured validated questionnaire was subsequently developed to assess the perceptions of nursing students. Factor loadings and calculated variances were examined to ensure convergent validity. Cronbach's alpha was used to calculate internal consistency reliability. Results: Factor loadings for each item in the model were above 0.70. All of the constructs had Cronbach's alpha values over 0.700 , except for enhanced assessment skills (Cronbach's alpha: 0.694). The variance extracted value was 0.815 for perceived usefulness, 0.800 for enhanced assessment skills, 0.687 for enhanced knowledge, attitudes and skills, 0.697 for enhanced confidence, 0.674 for enhanced counselling skills and 0.805 for future intention to use IMCI in a clinical setting. Conclusion: Overall, the results support the hypothetical model and indicate that nursing students perceive IMCI training to be beneficial and intend to apply IMCI-related knowledge and skills in clinical practice.

Keywords: Statistical Model; Nursing; Perceptions; Disease Management; Oman.

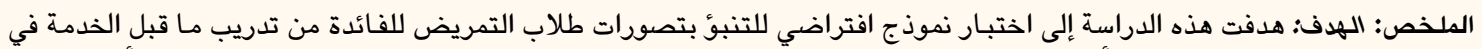

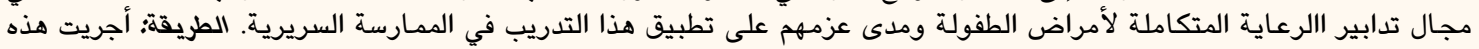

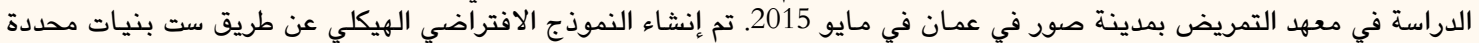

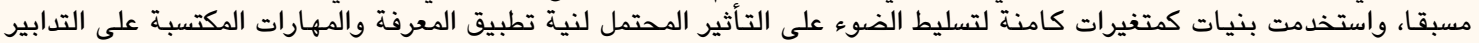

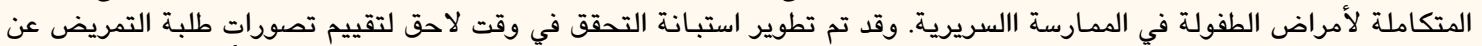

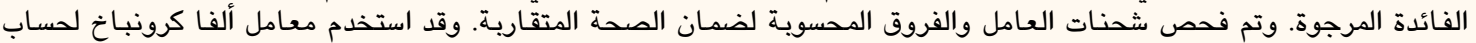

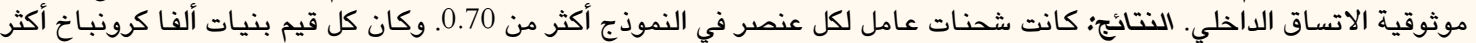

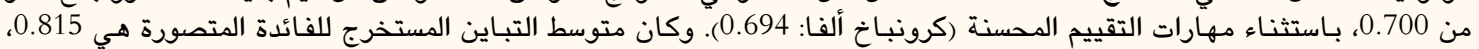

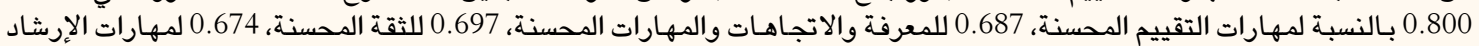

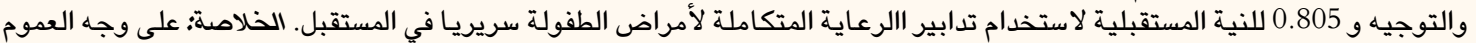

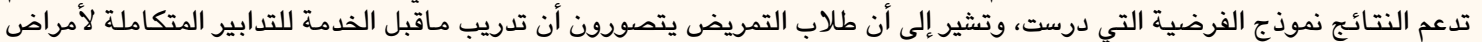

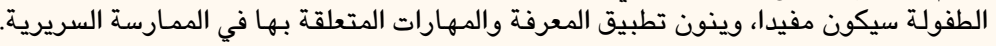

$$
\text { الكلمات المفتاحية: النموذج الإحصائي؛ التمريض؛ التصورات؛ علاج الأمراض؛ عمان. }
$$

\section{ADVANCES IN KNOWLEDGE}

The current study uses a quantitative approach for developing and validating a predictive structural data model.

The findings of this study add to the current knowledge base by highlighting nursing students' positive perceptions of Integrated Management of Childhood Illness (IMCI) training and their intentions to apply IMCI-related skills in clinical settings.

\section{Application to Patient Care}

Although there is rich evidence of the strengths of IMCI training, the extent to which IMCI-trained healthcare professionals apply these skills has not been reported. This is important as the application of IMCI-related skills may have a positive influence on paediatric health. 
C HILDHOOD ILlNESSES CONTINUE TO increase the global disease burden, especially in low- to middle-income countries. ${ }^{1}$ In the mid-1990s, the World Health Organization and United Nations International Children's Fund initiated the Integrated Management of Childhood Illness (IMCI) strategy in order to improve the health standards of children under five years of age. ${ }^{1,2}$ This approach focuses on improving health worker skills, refining healthcare systems, enhancing knowledge of child health among families and communities and disease-specific interventions. ${ }^{3}$ IMCI relies on trained healthcare professionals to improve symptom assessments, illness classifications and treatment needs and provide better counselling to caregivers. ${ }^{1,2}$

Since its introduction, IMCI has been implemented in several countries, including Uganda, Bangladesh, Brazil, Tanzania and Peru. ${ }^{1,4-8}$ In Tanzania, IMCI implementation resulted in a $13 \%$ reduction in the child mortality rate. ${ }^{5}$ Furthermore, IMCI training is believed to have improved the quality of child health in a number of countries. ${ }^{6-10}$ These promising findings have resulted in the implementation of IMCI in over 100 countries. ${ }^{11}$ In Oman, IMCI was introduced into the healthcare system in 1999. Since its implementation, a number of studies have examined the epidemiology and burden of specific conditions, such as diarrhoea, urinary tract infections, antimicrobial resistance and influenza; a few studies have also focused on other factors, such as patient-physician interactions and antibiotic policies. ${ }^{12-17}$

There are evident benefits of IMCI implementation for families and communities. In Nigeria, IMCI implementation was reported to be a cost-effective intervention. ${ }^{18}$ The positive effects of IMCI on case management and in improving illness classifications and enhancing skills in managing childhood illness are frequently reported.,10,18 However, limitations of healthcare systems, long duration of training courses, extended consultations and resistance from experienced doctors have been identified as barriers to the acceptance and practice of IMCI. ${ }^{19}$ In order to predict the effectiveness of IMCI implementation, it is essential to understand how IMCI-trained healthcare workers perceive IMCI training and whether they intend to use IMCI-related skills and knowledge in clinical practice. However, there is a lack of research on how healthcare professionals perceive IMCI training; this is important, as IMCI emphasises a new role for both doctors and nurses as educators as well as healthcare professionals. ${ }^{19}$ Moreover, healthcare professionals, such as nurses, play a vital role in paediatric health management. ${ }^{20}$
This study therefore aimed to test a hypothetical model to predict the perceived benefits of preservice IMCI training among nursing students and their intentions of applying IMCI-related skills and knowledge in future. It was hypothesised that IMCItrained nursing students would perceive IMCI training to useful in improving knowledge, skills and confidence, leading to the use of these skills in future clinical practice. This hypothesis was based on the theory of reasoned action, which suggests that the decision to perform a specific behaviour is strongly linked with the expected outcome or benefit of the behaviour. ${ }^{21,22}$

\section{Methods}

This study was carried out in May 2015 at the Sur Nursing Institute in Sur, Oman. A hypothetical structural model was developed with the help of six healthcare professionals, including two IMCI experts. The following six predefined constructs were used: perceived usefulness, enhanced assessment skills, enhanced knowledge, attitudes and skills (KAS), enhanced confidence, enhanced counselling skills and future intention to use IMCI in a clinical setting. These constructs were used as latent variables to highlight their probable impact on a formative variable (i.e. intention to apply IMCI-related knowledge and skills in practice). The model was designed to indicate relationships between the constructs.

Subsequently, a total of 114 nursing students were recruited via the distribution of posters at the Sur Nursing Institute. All of the nursing students had received pre-service IMCI training via workshops, lectures, laboratory sessions and field trips for a mean duration of $3.155 \pm 0.361$ years. The minimum sample size for this type of analysis was calculated using the heuristic method by multiplying by 10 the largest number of independent constructs influencing the dependent construct (i.e. six). ${ }^{23}$ Thus, the minimum sample size for the current study was calculated to be 60. An English-language structured questionnaire was created to assess the students' actual perceptions of IMCI training and intention to use this training in future practice. The questionnaire was developed and validated with the help of six practicing healthcare professionals to ensure that the language and terminology used in the questionnaire could be easily understood. The items were pretested by the healthcare professionals to ensure that each construct was loaded with three items. Participants completed and returned the questionnaires in sealed envelopes. 


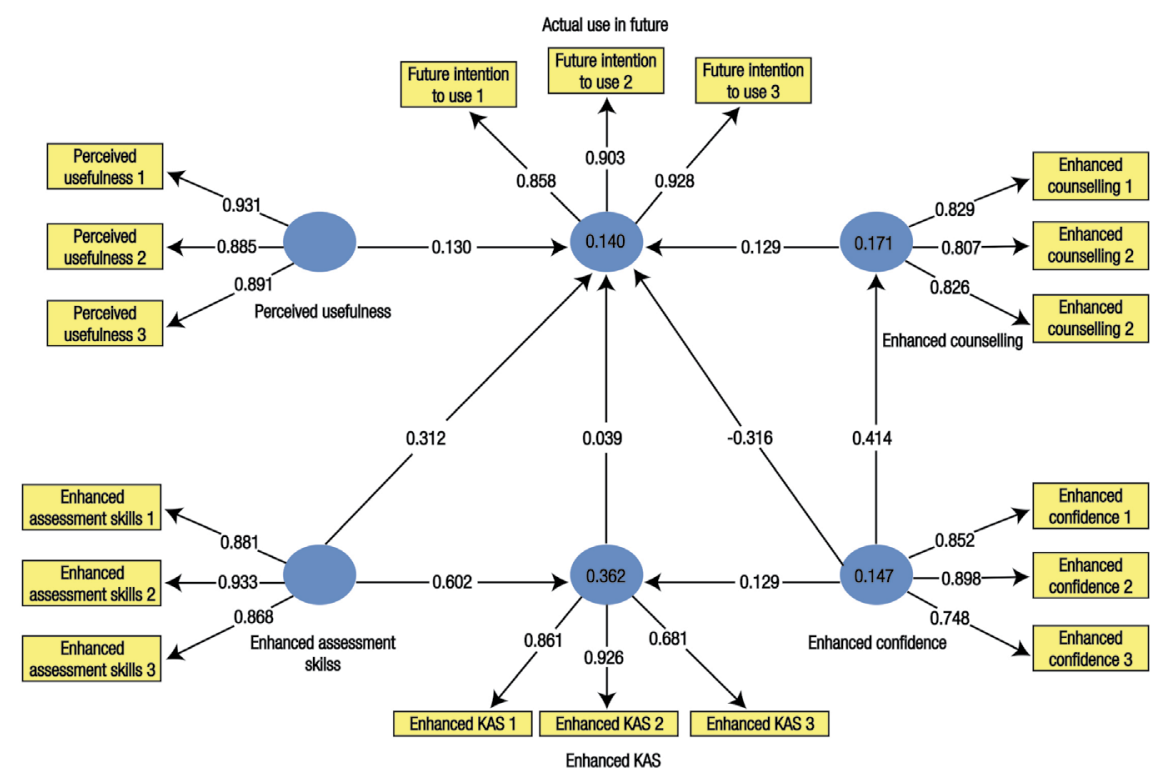

Figure 1: A hypothetical structural model to predict nursing students' perceptions of the usefulness of pre-service Integrated Management of Childhood Illness training and their intention to apply this training in future clinical practice. $K A S=$ knowledge, assessment and skills.

The reliability and validity of the model was analysed using Smart Partial Least Square software, Version 3.2.5 (SmartPLS GmbH, Bönningstedt, Germany). This software was chosen because it is appropriate for exploratory research aiming to test a new predictive model rather than re-examining existing models or theories. ${ }^{24}$ In the analysis, a twostep approach was applied (i.e. assessment of reliability and validity of the hypothetical model). ${ }^{25}$ The properties of the constructs were assessed in terms of factor loadings, discriminant validity and internal consistency. Factor loadings and calculated variances were examined to ensure convergent validity; factor loading and internal consistency values of over 0.700 were considered adequate. Cronbach's alpha was used to calculate the internal consistency reliability of the items. The Fornell-Larcker criterion was used to determine discriminant validity between the studied constructs. ${ }^{24}$ However, as previous research has indicated that the Fornell-Larcker criterion may not necessarily detect discriminant validity reliably, the heterotrait-monotrait (HTMT) ratio of correlations was also assessed. ${ }^{26}$ A HTMT value of below 0.90 indicated satisfactory discriminant validity. ${ }^{26}$ The effect sizes indicated by the path coefficients were noted to be either small (0.02), medium (0.15) or large (0.35).

Ethical approval for this study was obtained from the Ministry of Health of Oman. Each student gave written informed consent before participating in the study. The students were not offered any financial rewards or incentives for participating in the study.

\section{Results}

Of the 114 students invited to participate in the study, 110 completed the entire questionnaire (response rate: 96.5\%). There were 77 females (70\%) and 33 males (30\%). Figure 1 shows the relationships between the constructs in the hypothetical model. Factor loadings and calculated variances for each item exceeded 0.70 and 0.50 , respectively, indicating that all of the items loaded well. The average variance extracted value was above 0.607. All of the constructs had Cronbach's alpha values over 0.700 , except for enhanced assessment skills (Cronbach's alpha: 0.694). The composite reliability of all of the constructs in the model exceeded 0.821 [Table 1].

The discriminant validity of all of the correlations was below the threshold HTMT ratio value of 0.90 . Upon analysis of the path coefficients, enhanced assessment skills $(P<0.010)$, enhanced confidence $(P<0.050)$, enhanced counselling $(P<0.050)$ and perceived usefulness $(P<0.001)$ had a significant influence on future intention to use IMCI in a clinical setting. Finally, the cross-loadings of the items on their assigned latent variables were larger than any other loading. Therefore, the reliability and validity of the constructs in the model were acceptable.

The studied constructs were complexly interrelated. There was a $36.2 \%$ variance in the enhanced KAS construct. The enhanced KAS construct predicted $14.6 \%$ variance in enhanced confidence and $20.1 \%$ variance in future intention to apply IMCI-related 
Table 1: Latent variable coefficients and correlations of a hypothetical structural model to predict nursing students' perceptions of pre-service Integrated Management of Childhood Illness training

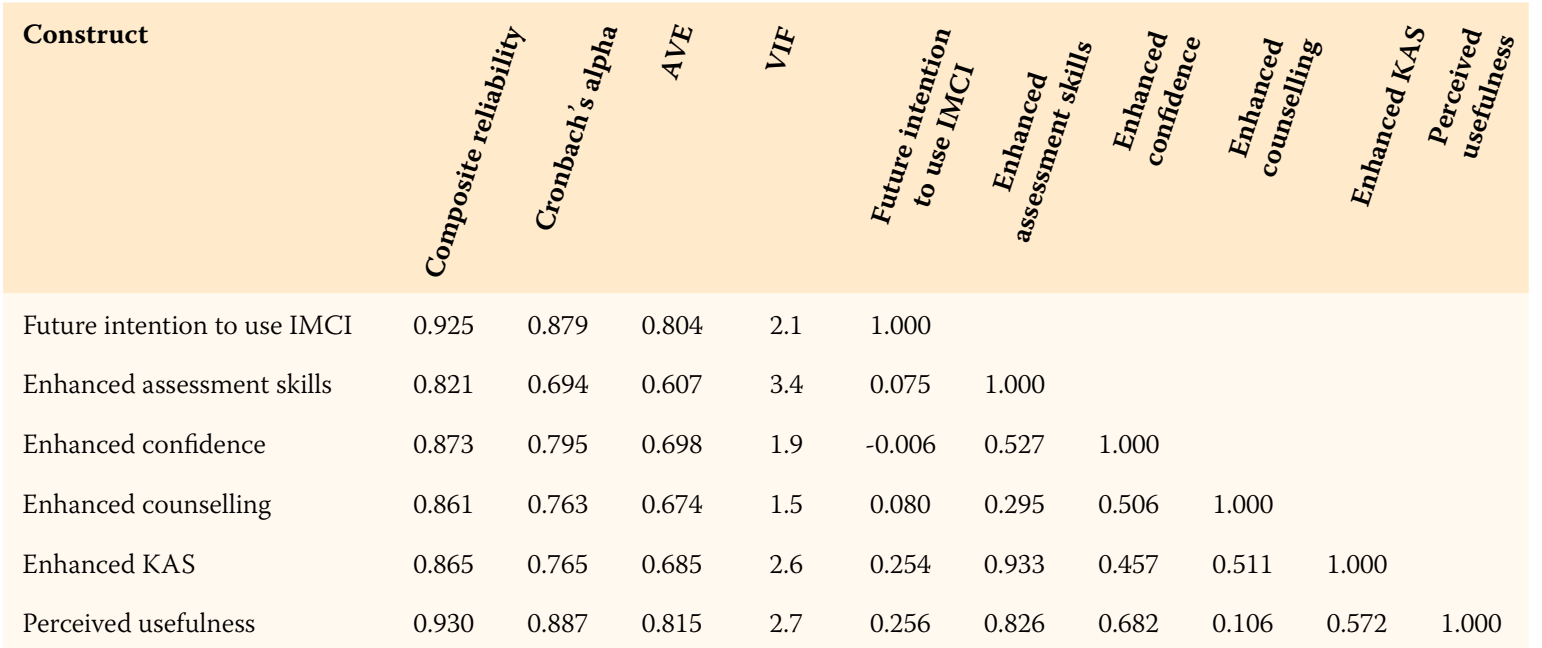

AVE = average variance extracted VIF = variance inflation factor; IMCI = Integrated Management of Childhood Illness; KAS = knowledge, assessment and skills.

knowledge and skills. The main direct contributors of the variance in future intention to apply IMCIrelated knowledge and skills were enhanced KAS (36.2\%), enhanced confidence (14.7\%) and enhanced counselling skills (17.1\%). When taken together, enhanced confidence and enhanced counselling skills resulted in a $31.8 \%$ variance in future intention to apply IMCI-related knowledge and skills. The $\mathrm{R}^{2}$ values were 36.2 for enhanced KAS, 14.7 for enhanced confidence, 17.1 for enhanced counselling and 14.0 for future intention to use IMCI. The constructs expressed significant variance (60\%) in future intention to apply IMCI-related knowledge and skills $(P<0.010)$. The

Table 2: Total effect of constructs in a hypothetical structural model to predict nursing students' perceptions of pre-service Integrated Management of Childhood Illness training

\begin{tabular}{llcc} 
Construct 1 & Construct 2 & $\begin{array}{l}\text { Total } \\
\text { effect }\end{array}$ & P value \\
$\begin{array}{l}\text { Enhanced } \\
\text { assessment skills }\end{array}$ & $\begin{array}{l}\text { Enhanced } \\
\text { confidence }\end{array}$ & 0.231 & $<0.001$ \\
$\begin{array}{l}\text { Enhanced } \\
\text { assessment skills }\end{array}$ & $\begin{array}{l}\text { Enhanced } \\
\text { counselling }\end{array}$ & 0.095 & 0.008 \\
$\begin{array}{l}\text { Enhanced } \\
\text { assessment skills }\end{array}$ & $\begin{array}{l}\text { Enhanced } \\
\text { KAS }\end{array}$ & 0.602 & $<0.001$ \\
$\begin{array}{l}\text { Enhanced } \\
\text { confidence }\end{array}$ & $\begin{array}{l}\text { Future } \\
\text { intention to } \\
\text { use IMCI }\end{array}$ & -0.263 & 0.016 \\
$\begin{array}{l}\text { Enhanced } \\
\text { confidence }\end{array}$ & $\begin{array}{l}\text { Enhanced } \\
\text { counselling }\end{array}$ & 0.414 & $<0.001$ \\
$\begin{array}{l}\text { Enhanced KAS } \\
\text { Enhanced } \\
\text { confidence }\end{array}$ & 0.383 & $<0.010$ \\
Enhanced KAS & $\begin{array}{l}\text { Enhanced } \\
\text { confidence }\end{array}$ & 0.158 & 0.002 \\
\hline
\end{tabular}

$K A S=$ knowledge, assessment and skills; $I M C I=$ Integrated Management of Childhood Illness. significance of the total effects are displayed in Table 2. Based on these statistical findings, the central hypothesis of the study was supported.

\section{Discussion}

The current study was performed to test a hypothetical model to predict perceived benefits of preservice IMCI training among trainee nurses and their subsequent intentions of using learned skills in clinical settings. To the best of the authors' knowledge, this is the first IMCI-related hypothetical model in the available literature. The results from the analysis substantially supported the hypothetical structural model. Factor loadings for each item in the model were above the minimum required threshold; ${ }^{27}$ moreover, the majority of the constructs had Cronbach's alpha values above the minimum cut-off level. ${ }^{25,28}$ Indeed, previous research has indicated that even reliability ranges of $0.5-0.6$ can be regarded as significant for experimental studies. ${ }^{29}$ Overall, the composite reliability of all constructs in the model exceeded the recommended value of $0.700 .{ }^{29}$ While the $R^{2}$ values were relatively low, lower $R^{2}$ values can nevertheless still indicate some level of significance. ${ }^{30}$ This is particularly true in any research work seeking to predict human behaviours and intentions. ${ }^{31}$ As the central assumption in the presented model was future intentions of healthcare professionals to use IMCIrelated knowledge and skills, even a lower $R^{2}$ value should be viewed as significant.

The current study revealed strong correlations between the studied constructs and intentions of using IMCI-related knowledge and skills in the future. Importantly, the current study found that the 
constructs expressed significant variance in future intention to apply IMCI-related knowledge and skills. In other words, this implies that nursing students are more likely to plan to apply IMCI-related skills in future if they perceive IMCI to be useful in helping improve their assessment skills, counselling skills, selfconfidence and KAS. All of the studied constructs were found to be contributors towards a positive intention to use the IMCI-related skills and knowledge. Based on this finding, it is likely that IMCI-trained nurses will actually apply the skills learned from pre-service IMCI training. However, it is critical to note that improved knowledge of caregivers and the synchronised func-tioning of the entire health system is necessary for the successful integration of IMCI., ${ }^{1,2}$

The findings of the current study add to the existing literature by highlighting the importance of IMCI among nursing students who will go on to practice in clinical settings after their graduation. To the best of the authors' knowledge, no previous studies have examined how nursing students perceive the usefulness of IMCI training. Moreover, this study is important in terms of furthering efforts to implement IMCI training in Oman. Although the findings from this study may not have a direct impact on practices, public health policy-makers are advised to take appropriate steps to integrate IMCI training at all medical and nursing institutions in the country. Governmental institutions and policies may help establish healthcare systems that embrace IMCI as a holistic approach. Healthcare policy-makers and senior medical professionals should consider the potential benefits of IMCI and encourage its implementation, allowing for sick children to receive timely, accurate and effective treatment. Future studies are recommended to identify factors that contribute to the high mortality rate of children under five years old. ${ }^{32}$

This study is subject to certain limitations. First, the studied sample was taken from a single educational institution so there may be potential selection bias. Second, due to the small sample size, it is hard to generalise the results. Third, while the statistical results indicate that IMCI-trained nursing students intend to apply their acquired skills in clinical settings, further investigation is necessary to establish whether these intentions hold true in the future. In future research, the authors recommend that efforts are made to investigate the extent to which IMCI-trained nurses apply their skills and knowledge in clinical settings and the factors which hinder them from doing so.

\section{Conclusion}

An IMCI-related hypothetical model was developed and evaluated for the first time. Perceived benefits of IMCI training were found to lead to an intention to apply related skills and knowledge in future clinical practice among nursing students. Overall, nursing students perceived IMCI to be a useful approach that could improve their skills, knowledge and confidence; as such, they intended to apply skills and knowledge learnt as result of this training in the future.

\section{CONFLICT OF INTEREST}

The authors declare no conflicts of interest.

\section{FUNDING}

No funding was received for this study.

\section{ACKNOWLEDGEMENTS}

The authors would like to thank all of the participants for their cooperation, as well as the relevant authorities of the Ministry of Health and Mr Mohammad M. Bahwan for their extended support. In addition, the authors appreciate the efforts of the healthcare professionals who aided in the development and validation of the questionnaire items. Finally, the authors wish to thank the management of Sur Nursing Institute for their support in carrying out this research.

\section{References}

1. Bryce J, el Arifeen S, Pariyo G, Lanata C, Gwatkin D, Habicht JP, et al. Reducing child mortality: Can public health deliver? Lancet 2003; 362:159-64. doi: 10.1016/S0140-6736 (03)13870-6

2. Gove S. Integrated management of childhood illness by outpatient health workers: Technical basis and overview The WHO Working Group on Guidelines for Integrated Management of the Sick Child. Bull World Health Organ 1997; $75: 7-24$

3. Bryce J, Boschi-Pinto C, Shibuya K, Black RE; WHO Child Health Epidemiology Reference Group. WHO estimates of the causes of death in children. Lancet 2005; 365:1147-52. doi: 10.1016/S0140-6736(05)71877-8.

4. Bryce J, Victora CG, Habicht JP, Vaughan JP, Black RE. The multi-country evaluation of the integrated management of childhood illness strategy: Lessons for the evaluation of public health interventions. Am J Public Health 2004; 94:406-15. doi: 10.2105/AJPH.94.3.406.

5. Armstrong Schellenberg JR, Adam T, Mshinda H, Masanja H, Kabadi G, Mukasa O, et al. Effectiveness and cost of facilitybased Integrated Management of Childhood Illness (IMCI) in Tanzania. Lancet 2004; 364:1583-94. doi: 10.1016/S01406736(04)17311-X.

6. Amaral J, Leite AJ, Cunha AJ, Victora CG. Impact of IMCI health worker training on routinely collected child health indicators in northeast Brazil. Health Policy Plan 2005; 20:i42-8. doi: 10.1093/heapol/czi058. 
7. Pariyo GW, Gouws E, Bryce J, Burnham G; Uganda IMCI Impact Study Team. Improving facility-based care for sick children in Uganda: Training is not enough. Health Policy Plan 2005; 20:i58-68. doi: 10.1093/heapol/czi051.

8. Arifeen SE, Hoque DM, Akter T, Rahman M, Hoque ME, Begum $\mathrm{K}$, et al. Effect of the Integrated Management of Childhood Illness strategy on childhood mortality and nutrition in a rural area in Bangladesh: A cluster randomised trial. Lancet 2009; 374:393-403. doi: 10.1016/S0140-6736(09)60828-X

9. Wagstaff A, Bustreo F, Bryce J, Claeson M; WHO-World Bank Child Health and Poverty Working Group. Child health: Reaching the poor. Am J Public Health 2004; 94:726-36. doi: 10.2105/AJPH.94.5.726.

10. Naimoli JF, Rowe AK, Lyaghfouri A, Larbi R, Lamrani LA. Effect of the Integrated Management of Childhood Illness strategy on health care quality in Morocco. Int J Qual Health Care 2006; 18:134-44. doi: 10.1093/intqhc/mzi097.

11. Chopra M, Binkin NJ, Mason E, Wolfheim C. Integrated management of childhood illness: What have we learned and how can it be improved? Arch Dis Child 2012; 97:350-4. doi: 10.1136/archdischild-2011-301191.

12. Patel PK, Mercy J, Shenoy J, Ashwini B. Factors associated with acute diarrhoea in children in Dhahira, Oman: A hospitalbased study. East Mediterr Health J 2008; 14:571-8.

13. World Health Organization Department of Child and Adolescent Health and Development. Urinary tract infections in infants and children in developing countries in the context of IMCI. From: whqlibdoc.who.int/hq/2005/WHO_FCH CAH_05.11.pdf Accessed: Aug 2016.

14. Prakash KP. Epidemiology and antimicrobial resistance of enteric pathogens in Dhahira Region, Oman. Iran J Public Health 2008; 37:60-9.

15. Al-Awaidy S, Hamid S, Al Obaidani I, Al Baqlani S, Al Busaidi S, Bawikar S, et al. The burden of influenza-associated hospitalizations in Oman, January 2008-June 2013. PLoS One 2015; 10:e0144186. doi: 10.1371/journal.pone.0144186.

16. Abdulhadi N, Al-Shafaee AM, Ostenson CG, Vernby A, Wahlström R. Quality of interaction between primary healthcare providers and patients with type 2 diabetes in Muscat, Oman: An observational study. BMC Fam Pract 2006; 7:72. doi: 10.1186/1471-2296-7-72.

17. Al-Fannah F, Khandekar R, Kurup P, Shah S. Preferral antibiotic treatment policy to be adopted in the Integrated Management of Childhood Illness strategy in all the developing countries? Oman Med J 2009; 24:248-55. doi: 10.5001/omj.2009.51.

18. Ebuehi OM. Health care for under-fives in Ile-Ife, south-west Nigeria: Effect of the Integrated Management of Childhood Illness (IMCI) strategy on growth and development of underfives. Afr J Prim Health Care Fam Med 2009; 1:029. doi: 10.41 02/phcfm.v1i1.29.

19. Saloojee H. Integrated management of childhood illness (IMCI): Traditional versus new approaches to clinical care. Contin Med Educ 2007; 25:172-5.
20. Fujimori E, Higuchi $\mathrm{CH}$, Carneiro TA, Borges AL, Chiesa AM, Veríssimo MD, et al. Integrated Management of Childhood Illness (IMCI): Knowledge and practice of nurses who have graduated from School of Nursing at University of São Paulo A case study. Online Braz J Nurs 2010; 9:1. doi: 10.5935/16764285.20102657.

21. Fishbein M. A theory of reasoned action: Some applications and implications. Nebr Symp Motiv 1980; 27:65-116.

22. Madden TJ, Ellen PS, Ajzen I. A comparison of the the theory of planned behavior and the the theory of reasoned action. Personal Soc Psychol Bull 1992; 18:3-9. doi: 10.1177/0146167292181001.

23. Chin WW, Marcolin BL, Newsted PR. A partial least squares latent variable modeling approach for measuring interaction effects: Results from a Monte Carlo simulation study and an electronic-mail emotion/adoption study. Inf Syst Res 2003; 14:189-217. doi: 10.2753/MTP1069-6679190202.

24. Hair JF, Ringle CM, Sarstedt M. PLS-SEM: Indeed a silver bullet. J Mark Theory Pract 2011; 19:139-52.

25. Anderson JC, Gerbing DW. Structural equation modeling in practice: A review and recommended two-step approach. Psychol Bull 1988; 103:411-23. doi: 10.1037/0033-2909.103. 3.411 .

26. Henseler J, Ringle CM, Sarstedt M. A new criterion for assessing discriminant validity in variance-based structural equation modeling. J Acad Mark Sci 2015; 43:115-35. doi: 10.1007/s11747-014-0403-8.

27. Langrial S. Persuasive subtleties of social networking sites: Design implications for behavior change interventions. In: Theng LB, Ed. Assistive Technologies for Physical and Cognitive Disabilities. Hershey, Pennsylvania, USA: IGI Global, 2014. Pp. 191-210. doi: 10.4018/978-1-4666-7373-1.ch010.

28. Gliem JA, Gliem RR. Calculating, interpreting, and reporting Cronbach's alpha reliability coefficient for Likert-type scales. From: scholarworks.iupui.edu/handle/1805/344 Accessed: Aug 2016.

29. Nunnally JC, Bernstein IH. Psychometric Theory, 3rd ed. New York, USA: McGraw-Hill, 1994. Pp. 248-92.

30. Vinzi VE, Trinchera L, Amato S. PLS path modeling: From foundations to recent developments and open issues for model assessment and improvement. In: Vinzi VE, Chin WW, Henseler J, Wang H, Eds. Handbook of Partial Least Squares: Concepts, methods and applications. Berlin, Germany: Springer, 2010. Pp. 47-82. doi: 10.1007/978-3-540-32827-8_3.

31. Onditi AA. Relationship between customer personality, service features and customer loyalty in the banking sector: A survey of banks in Homabay County, Kenya. Int J Bus Soc Sci 2013; 4:132-50.

32. Black RE, Cousens S, Johnson HL, Lawn JE, Rudan I, Bassani DG, et al. Global, regional, and national causes of child mortality in 2008: A systematic analysis. Lancet 2010; 375:1969-87. doi: 10.1016/S0140-6736(10)60549-1. 